\title{
Clinical Study of the Incidence of Preterm Premature Rupture of Membranes and Maternal and Fetal Outcome
}

\author{
N. Mamatha ${ }^{1}$, Arjumand Bano ${ }^{2}$, Sharada Sabavath ${ }^{3}$ \\ 1, 2, 3 Department of Obstetrics and Gynaecology, Chalmeda Anand Rao Institute of Medical Sciences, \\ Bommakal, Karimnagar, Telangana, India.
}

\section{ABSTRACT}

\section{BACKGROUND}

Preterm premature rupture of membranes is one of the important causes of premature birth that can result in high perinatal morbidity and mortality along with maternal morbidity. The definition of premature rupture of membranes is rupture of membranes before labour and before 37 weeks of gestation is referred as Preterm PROM. If the membrane rupture is after 37 weeks of gestation, it is Term PROM. The incidence of PPROM ranges from 3 - $10 \%$ of all deliveries and it contributes to 30 $40 \%$ of all preterm births.

\section{METHODS}

A prospective observational study of clinical analysis of the PPROM in 100 cases of 28 - 37 weeks of gestation which were delivered by caesarean section was conducted from 2018 October to 2019 September in the Department of Obstetrics and Gynaecology of Chalmeda Anand Rao Institute of Medical Sciences, Bommakal, Karimnagar.

\section{RESULTS}

Prevalence of PPROM in the study is $7.8 \%$. Intra amniotic infection was seen in $32 \%$. The mean latency period from rupture of membranes to delivery is $3.78+2.74$ days. $25 \%$ neonates were delivered by caesarean section. There was a total of $12 \%$ perinatal deaths, still births - 4\%,10\% - early neonatal deaths.

\section{CONCLUSIONS}

In the current study, the prevalence of PPROM was $7.8 \%$. Careful antenatal monitoring, detection and prompt treatment of infection is necessary. Strict septic precautions, appropriate therapy, regular antenatal follow up are important factors in the prevention of PPROM. Close antenatal monitoring, identification of risk factors like cervicovaginal infection and their management play an important role in the prevention of PPROM.

\section{KEY WORDS}

Preterm Premature Rupture of Membranes, Initial Workup, Maternal Factors, Fetal Factors
Corresponding Author: Dr. Sharada Sabavath.

Ho, No. 2-22, Amangal, Vittaipally, RangaReddy, Telangana- 509321, India. E-mail: smilesharada16@gmai.com

DOI: $10.14260 /$ jemds/2020/704

How to Cite This Article:

Mamatha N, Bano A, Sabavath S. Clinical study of the incidence of preterm premature rupture of membranes and maternal and fetal outcome. J Evolution Med Dent Sci 2020;9(43):3210-3213, 10.14260/jemds/2020/704

Submission 15-07-2020,

Peer Review 15-09-2020,

Acceptance 23-09-2020,

Published 26-10-2020.

Copyright (C) 2020 N. Mamatha et al. This is an open access article distributed under Creative Commons Attribution License [Attribution 4.0 International (CC BY 4.0)] 


\section{BACKGROUND}

The normal development, structural integrity and function of the fetal membranes are essential for the normal progress and outcome of pregnancy. Its most important function is to remain intact until the onset of labour at term in order to maintain the protective intrauterine fluid environment. In most of pregnancies labour begins at term in the presence of intact foetal membranes. Without interventions their spontaneous rupture usually occurs at the end of first stage of labour. In $10 \%$ of pregnancies at term fetal membranes failed to maintain their structural integrity, resulting in their prelabour rupture. If membrane ruptures before labour and before 37 weeks of gestation it is referred as PRETERM PROM (PPROM). ${ }^{1}$ If the membrane ruptures after 37 weeks of gestation it is called TERM PROM. The incidence ranges from $3.0-10.0 \%$ of all deliveries. ${ }^{2}$ Preterm PROM complicates up to $2 \%$ of all pregnancies and contributes to $30-40 \%$ of all preterm births. ${ }^{3}$ PPROM is one of the most important cause of preterm birth that can result in prenatal morbidity and mortality along with maternal morbidity. 4

There are numerous risk factors for PPROM such as intrauterine infections at early gestational age, lower socioeconomic status of pregnant women, inadequate prenatal care and inadequate nutrition during pregnancy, sexually transmitted infections, vaginal bleeding during pregnancy and smoking.5,6 Both mother and fetus are at greater risk of infections after PPROM. The fetal and neonatal morbidity risks are significantly affected by severity of oligo hydramnios during latency and gestation at PROM. The primary complication for the mother is risk of infection and for the fetus and newborn is prematurity, fetal distress, cord compression, deformation and altered pulmonary development leading to pulmonary hyperplasia and pulmonary hypertension, necrotizing enterocolitis and neurological disorders. Infectious morbidities in mother, fetus and new born have been related to both PROM and prolonged rupture of membranes. ${ }^{2}$ The aim was to evaluate the maternal and prenatal complications in preterm premature rupture of membranes between 25 to 37 weeks' gestation.

\section{Objectives}

- To find out the incidence of PPROM in hospital delivery groups

- To assess the outcome of labour in PPROM.

- To find out the maternal and perinatal morbidity trends in PPROM

\section{METHODS}

This is a prospective observational study of the preterm rupture of membranes conducted among 100 cases of singleton pregnancy, between 28 - 37 weeks of gestation at the Department of Obstetrics and Gynaecology of a tertiary care centre between October 2018 and September 2019. Written informed consent was obtained from patients included in the study. The study was approved by IEC Reg. No. CAIMS / 01 / IEC / 2020 / 001.

\section{Inclusion Criteria}

- $\quad$ Singleton pregnancy between 28 - 37 weeks of gestational age with preterm premature rupture of membrane.

\section{Exclusion Criteria}

- Multiple pregnancies

- Intrauterine growth restrictions

- Uterine anomalies, fetal anomalies

- Myoma of uteri

- Hypertensive disorders \& pregnancy induced hypertension

- Gestational diabetes

- Antepartum haemorrhage

- Cardiac diseases

\section{Statistical Analysis}

In this study the data was analysed statistically by computing proportions and percentages. The statistical inference was obtained by computing Chi-square test and considered statistically significant if the $p$ value was $<0.05$.

\section{RESULTS}

\begin{tabular}{|c|c|c|c|c|c|c|c|}
\hline $\begin{array}{l}\text { Bishop } \\
\text { Score }\end{array}$ & $\begin{array}{l}\text { No. of } \\
\text { Cases }\end{array}$ & $\begin{array}{l}\text { Normal } \\
\text { Delivery }\end{array}$ & $\%$ & $\begin{array}{l}\text { Outlet } \\
\text { Forceps }\end{array}$ & $\%$ & LSCS & $\%$ \\
\hline $0-5$ & 52 & 24 & $46 \%$ & 8 & $15 \%$ & 20 & $38 \%$ \\
\hline $6-10$ & 41 & 34 & $83 \%$ & 2 & $5 \%$ & 5 & $12 \%$ \\
\hline $11-13$ & 7 & 7 & $100 \%$ & 0 & 0 & 0 & 0 \\
\hline Total & 100 & 65 & & 10 & & 25 & \\
\hline \multicolumn{8}{|c|}{$\begin{array}{c}\text { Table 1. Analysis of PPROM Cases According to Bishop Score } \\
\text { at the Time of Admission and Mode of Delivery }\end{array}$} \\
\hline
\end{tabular}

\begin{tabular}{|c|c|c|c|c|c|c|c|}
\hline 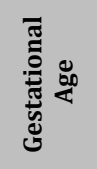 & 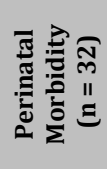 & $\partial^{0}$ & 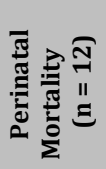 & $\partial^{0}$ & 苟 & 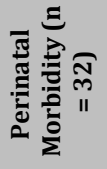 & 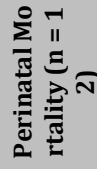 \\
\hline $\begin{array}{l}28-32 \\
\text { wks. } \\
(n=35)\end{array}$ & 21 & 65.75 & 10 & 83.75 & $\begin{array}{l}<2 \text { Kgs. } \\
(n=50)\end{array}$ & 21 & 10 \\
\hline $\begin{array}{l}33-35 \\
\text { wks. } \\
(n=32)\end{array}$ & 10 & 31.25 & 2 & 16.25 & $\begin{array}{l}2.1-2.5 \\
\text { Kgs. (n = } \\
26)\end{array}$ & 7 & 2 \\
\hline $\begin{array}{l}36-37 \\
\text { wks. } \\
(\mathrm{n}=33)\end{array}$ & 1 & 3 & 0 & 0 & $\begin{array}{c}>2.5 \text { Kgs. } \\
(n=24)\end{array}$ & 4 & 0 \\
\hline \multicolumn{8}{|c|}{$\begin{array}{l}\text { Table 2. Analysis of Perinatal Outcome in PPROM Cases According to } \\
\text { Gestational Age (at the Time of PPROM) and Birth Weight } \\
\text { hi square value: } 60.7\end{array}$} \\
\hline
\end{tabular}

\begin{tabular}{|c|c|c|c|c|c|}
\hline $\begin{array}{l}\text { Duration of } \\
\text { PPROM } \\
\text { in Hours }\end{array}$ & $\begin{array}{c}\text { No. } \\
\text { of Cases of Mate } \\
\text { rnal Morbidity }\end{array}$ & $\%$ & $\begin{array}{l}\text { Duration } \\
\text { of } \\
\text { PPROM }\end{array}$ & $\begin{array}{l}\text { Perinatal } \\
\text { Morbidity }\end{array}$ & $\begin{array}{l}\text { Perinatal } \\
\text { Mortality }\end{array}$ \\
\hline$<12$ hrs. $(\mathrm{n}=17)$ & 1 & $5.8 \%$ & $<12$ hrs. & $17 \%$ & $6.8 \%$ \\
\hline $\begin{array}{l}13-24 \text { hrs. } \\
(\mathrm{n}=18)\end{array}$ & 3 & $17.6 \%$ & $12-24$ hrs. & $27.7 \%$ & $10.5 \%$ \\
\hline \multirow[t]{3}{*}{$>24$ hrs. $(n=63)$} & 13 & $76.4 \%$ & $25-48$ hrs. & $35 \%$ & $12.5 \%$ \\
\hline & & & $>48 \mathrm{hrs}$ & $38.7 \%$ & $13 \%$ \\
\hline & & & $>1$ week & $41.6 \%$ & $14 \%$ \\
\hline \multicolumn{6}{|c|}{$\begin{array}{l}\text { Table 3. Analysis of PPROM According to Duration of PPROM } \\
\text { Maternal Morbidity and Perinatal Morbidity and Mortality }\end{array}$} \\
\hline
\end{tabular}

Total number of deliveries were 1288. Out of which PPROM cases were 100 . The prevalence of PPROM in the study is 7.8 $\%$. Intra amniotic infection seen in $32 \%$. The mean latency 
period from rupture of membranes to delivery is 7 days. $25 \%$ neonates were delivered by caesarean section. There was a total of $12 \%$ perinatal deaths $4 \%$ stillbirth, $10 \%$ early neonatal deaths.

\begin{tabular}{|c|c|c|c|}
\hline $\begin{array}{l}\text { Different } \\
\text { Studies }\end{array}$ & $\begin{array}{c}\text { Prevalence } \\
\text { of PPROM }\end{array}$ & $\begin{array}{l}\text { Various } \\
\text { Studies }\end{array}$ & $\begin{array}{l}\text { Neonatal Sepsis in } \\
\text { Mother with HSV } \\
\text { Positive }\end{array}$ \\
\hline $\begin{array}{l}\text { Minakshi Rana et } \\
\text { al (2014) }\end{array}$ & $8.9 \%$ & $\begin{array}{l}\text { Swathi Pandey et } \\
\text { al (2000) }\end{array}$ & $25 \%$ \\
\hline $\begin{array}{l}\text { Swathi Pandey et } \\
\text { al }(2000)\end{array}$ & $7.7 \%$ & $\begin{array}{c}\text { Taralekha Vaishal } \\
\text { i et al (2014) }\end{array}$ & $12.9 \%$ \\
\hline $\begin{array}{c}\text { Kamala Jayaram et } \\
\text { al (2001) }\end{array}$ & $3.8 \%$ & $\begin{array}{l}\text { Minakshi Rana et } \\
\text { al (2014) }\end{array}$ & $33 \%$ \\
\hline $\begin{array}{c}\text { Anjana Devi et al } \\
(1996)\end{array}$ & $5 \%$ & & \\
\hline Present Study & $7.8 \%$ & Present Study & $40 \%$ \\
\hline \multicolumn{4}{|c|}{ Table 4. Analysis of PPROM Cases According to Maternal Complications } \\
\hline
\end{tabular}

\section{DISCUSSION}

PROM occurring at or near term is associated with insignificant adverse effects on the mother and fetus as in 80 $90 \%$ spontaneous onset of labour ensures. PROM near term is a management dilemma. In women with rupture of membranes remote from term $(<34$ weeks) prematurity as well as sepsis puts both the mother and fetus at risk. However, with use of prophylactic antibiotics and steroids, a policy of conservative management has proven beneficial to both the mother and fetus. PPROM is one of the difficult problems faced by the obstetricians because the management depends upon several variables such as gestational age, fetal presentations, estimated foetal weight, amount of liquor, state of cervix, type of pelvis, duration of draining, presence / absence of amnionitis, previous obstetric history. The reported incidence of PROM in the literature varies widely between $3-18.5 \%$ (GUNN et al 1970). The present study conducted in a tertiary centre revealed a prevalence of PPROM to be $7.8 \%$. This is comparable to the prevalence rate of the studies conducted by Minakshi Rana (8.3 \%), Swathi Pandey (7.7 \%) and Ajanadevi (5\%), but the study by Kamala Jayaram shows a prevalence of $3.8 \%$, which is low compared to our study.

The prevalence of PPROM is found by Canavan to be $3 \%$ \& $1 \%$ at Parkland memorial hospital 7 this low rate of prevalence of PPROM may be due to socioeconomic status, regular antenatal check-ups, prompt identification, \& treatment of vaginal infections. In present study on analysing the infectious complications in the mother and fetus, it was observed that women with positive growth in their initial vaginal samples had significantly higher rates of chorioamnionitis (33\%), postpartum sepsis $(47 \%)$ and neonatal sepsis (40\%) compared with those who had no growth $(p=0.016)$. It implies relative safety of conservative management in women with PPROM with initial vaginal cultures negative. With the use of antibiotics, the development of infectious complications can be further curtailed. However, women with positive culture need to be managed cautiously. The study of Taralekha Vaishali et al $(2014)^{8}$ showed $12.9 \%$ cases of neonatal sepsis and the mother of all these neonates had growth in HVS (High Vaginal Swab) suggesting vaginal infection. The incidence of neonatal sepsis was less as the neonate after birth received injectable antibiotics. The study of Minakshi Rana et al (2014) 9 showed $33 \%$ of neonatal sepsis and the mother of all these neonates had growth in HVS suggesting vaginal infection.

\begin{tabular}{|c|c|c|c|c|}
\hline $\begin{array}{c}\text { Maternal } \\
\text { Complications }\end{array}$ & $\begin{array}{l}\text { No. of } \\
\text { Cases }\end{array}$ & $\%$ & Various Studies & Chorioamnionitis \\
\hline Chorioamnionitis & 10 & $58 \%$ & $\begin{array}{c}\text { Anjana Devi et al } \\
\text { (1996) }\end{array}$ & $5.6 \%$ \\
\hline \multirow[t]{5}{*}{ Postpartum Sepsis } & 7 & $42 \%$ & Piya Rai et al (1997) & $14 \%$ \\
\hline & & & $\begin{array}{l}\text { Swathi Pandey et al } \\
\qquad(2000)\end{array}$ & $6 \%$ \\
\hline & & & $\begin{array}{c}\text { Minakshi Rana et al } \\
\text { (2014) }\end{array}$ & $9.5 \%$ \\
\hline & & & $\begin{array}{l}\text { Taralekha Vaishali et } \\
\text { al (2014) }\end{array}$ & 0 \\
\hline & & & Present Study & $10 \%$ \\
\hline \multicolumn{5}{|c|}{$\begin{array}{l}\text { Table 5. Analysis of PPROM Cases According to } \\
\text { Maternal Complications }\end{array}$} \\
\hline \multicolumn{5}{|c|}{ Chi square value : 8.31} \\
\hline
\end{tabular}

Chorioamnionitis is a major problem which can lead to intra partum and post-partum sepsis and even septicaemia. It is an important complication of PROM with an incidence of 3 - $31 \%$. In the present study, the incidence of chorioamnionitis was $10 \%$ and it was comparable to study of Minakshi Rana et al $(2014)^{9}(10 \%)$ and various other studies as shown above.

In the study of Tara Lekha Vaishali et al (2014)8, there was no case of clinical chorioamnionitis. This probably was because all the patients in the study were given prophylactic antibiotics and were delivered before $24 \mathrm{hrs}$ from the onset of PROM. In women who have clinical chorioamnionitis, about $40 \%$ will also develop postpartum endometritis. The incidence of postpartum maternal sepsis in PPROM has been reported to be between $0-3 \%$ (Shumway etal 1999). In present study 7 cases had postpartum sepsis.

According to Bishop score, in the present study, normal delivery was $65 \%$, outlet forceps $10 \%$ and LSCS (Lower Segment Cesarian Section) $25 \%$ which is comparable to the study by Swathi Pandey (2000) (LSCS $31 \%$ ) and Kamala Jayaram (2001) (ND $74 \%$ outlet forceps $11 \%$, and LSCS $15 \%)$. The LSCS rate was very high in the study of Anjana Devi (45\%). The mode of delivery in present study is also comparable with the mode of delivery in general population delivered in our hospital (ND $62.7 \%$, LSCS $26.2 \%$ and outlet forceps $11.1 \%$ ). The higher incidence of LSCS in our hospital is because of our hospital being one of the main referral centre for women and children. Therefore the overall incidence of complicated labour is higher.

In present study according to gestational age, the overall perinatal mortality was $28.5 \%$ and morbidity was $60 \%$ at 28 - 32 weeks of gestational age and perinatal mortality was $0 \%$ and morbidity was $3 \%$ at $36-37$ weeks. It has been demonstrated that, earlier the gestational age at the time of PPROM, worse is the perinatal outcome. As expected we found that, as gestational age increases, the risk of adverse perinatal outcome in women receiving uniform administration of steroids and antibiotics decline.

According to birth weight, our results suggested that for women who presented with PPROM the overall effect of expectant management is beneficial. Outcome of neonates who delivered after 34 weeks of gestation was optimum. A significant increase was seen in birth weight with a significant reduction in duration of NICU (Neonatal Intensive Care Unit) stay. Thus, we suggest that immediate delivery after PPROM should not be practiced especially in developing countries like India. Rather patient should be kept on expectant management for longer possible duration possibly 34 weeks over even up to 36 weeks. ${ }^{10,11}$ In the present study perinatal morbidity and mortality increases with duration PPROM. But it was 
statistically not significant, which is comparable to the study of Seem Singhal et al (2012). ${ }^{12}$

\section{CONCLUSIONS}

In the current study the prevalence of PPROM was $7.8 \%$. PPROM occurring at or near term is associated with insignificant adverse effect on the mother and fetus as in 80 $90 \%$ spontaneous onset of labour ensures. It was observed that the mean latency period decreased from 3.78 days at 28 to 32 weeks to 1.06 days at $36-37$ weeks. On analysing infectious complications, women with positive growth in their initial vaginal samples had significantly higher rates of postpartum sepsis and neonatal sepsis compared with those who had no growth. The maternal morbidity increases as the duration of PPROM increases.

Data sharing statement provided by the authors is available with the full text of this article at jemds.com.

Financial or other competing interests: None.

Disclosure forms provided by the authors are available with the full text of this article at jemds.com.

\section{REFERENCES}

[1] Practice bulletin no. 139: premature ruptures of membranes. Obstet Gynecol 2013;122(4):918-30.

[2] Kaur BA, Vats U, Nandanwar YS. Role of serial ultrasound assessment on PROM patients and its outcome (prospective study). Bombay Hospital Journal 2009;51(2):163-6.

[3] Morris JM, Roberts CL, Crowther CA, et al. Protocol for the immediate delivery versus expectant care of women with preterm prelabour rupture of the membranes close to term (PPROMT) Trial. BMC Pregnancy Childbirth 2006;6:9.

[4] Noor S, Nazar AF, Bashir R, et al. Prevalence of PPROM and its outcome. J Ayub Med Coll Abbottabad 2008;19(4):147.

[5] McGregor JA, French JI. Evidence-based prevention of preterm birth and rupture of membranes: infection and inflammation J Soc Obstet Gynecol Can 1997;19:835-52.

[6] Novak-Antolic Z, Pajntar M, Verdenik I. Rupture of membranes and postpartum infection. Eur J Obstet Gynecol Reprod Biol 1997;71(2):141-6.

[7] Canavan TP, Simhan HN, Caritis S. An evidence-based approach to the evaluation of premature rupture of membranes: Part II. Obstet Gynaecol Surv 2004;59(9):678-89.

[8] Vaishali T, Girija W, Pooja DS, et al. Vaginal Infections As a Cause For Preterm Labour, PPROM, PROM. International Jounal of Advanced Research 2014;2(7):1092-6.

[9] Rana M, Patra S, Puri M, et al. Fetomaternal outcome in preterm premature rupture of membrane. Int J Infertil Fetal Med 2014;5(1):18-21.

[10] Pasquier JC, Picaud JC, Rabilloud M, et al. Neonatal outcomes after elective delivery management of preterm premature rupture of the membranes before 34 weeks' gestation (DOMINOS study). Eur J Obstet and Gynecol Reprod Biol 2009;143(1):18-23.

[11] Ye G, Jiang Z, Lu S, et al. Premature infants born after preterm premature rupture of membranes with 24-34 weeks of gestation: a study of factors influencing length of neonatal intensive care unit stay. J Maternal Fetal Neonatal Med 2011;24(7):960-5.

[12] Singal S, Puri M, Gami N. An analysis of factors effecting the duration of latency period and its impact on neonatal outcome in patients with PPROM. Int J Infertility Foetal Med 2012;3(3):87-91. 